\title{
Acute care inpatients with long-term delayed-discharge: evidence from a Canadian health region
}

\author{
Andrew P Costa ${ }^{1,2^{*}}$, Jeffrey W Poss ${ }^{1,2}$, Thomas Peirce ${ }^{2}$ and John P Hirdes ${ }^{1}$
}

\begin{abstract}
Background: Acute hospital discharge delays are a pressing concern for many health care administrators. In Canada, a delayed discharge is defined by the alternate level of care (ALC) construct and has been the target of many provincial health care strategies. Little is known on the patient characteristics that influence acute ALC length of stay. This study examines which characteristics drive acute ALC length of stay for those awaiting nursing home admission.

Methods: Population-level administrative and assessment data were used to examine 17,111 acute hospital admissions designated as alternate level of care (ALC) from a large Canadian health region. Case level hospital records were linked to home care administrative and assessment records to identify and characterize those ALC patients that account for the greatest proportion of acute hospital ALC days.

Results: ALC patients waiting for nursing home admission accounted for $41.5 \%$ of acute hospital ALC bed days while only accounting for $8.8 \%$ of acute hospital ALC patients. Characteristics that were significantly associated with greater ALC lengths of stay were morbid obesity (27 day mean deviation, $99 \% \mathrm{Cl}= \pm 14.6$ ), psychiatric diagnosis (13 day mean deviation, $99 \% \mathrm{Cl}= \pm 6.2$ ), abusive behaviours (12 day mean deviation, $99 \% \mathrm{Cl}= \pm 10.7$ ), and stroke (7 day mean deviation, $99 \% \mathrm{Cl}= \pm 5.0$ ). Overall, persons with morbid obesity, a psychiatric diagnosis, abusive behaviours, or stroke accounted for $4.3 \%$ of all ALC patients and $23 \%$ of all acute hospital ALC days between April $1^{\text {st }} 2009$ and April 1 15t, 2011 . ALC patients with the identified characteristics had unique clinical profiles.

Conclusions: A small number of patients with non-medical days waiting for nursing home admission contribute to a substantial proportion of total non-medical days in acute hospitals. Increases in nursing home capacity or changes to existing funding arrangements should target the sub-populations identified in this investigation to maximize effectiveness. Specifically, incentives should be introduced to encourage nursing homes to accept acute patients with the least prospect for community-based living, while acute patients with the greatest prospect for community-based living are discharged to transitional care or directly to community-based care.
\end{abstract}

Keywords: Delayed discharge, Alternate level of care, Vulnerable elderly, Length of stay, Acute care, interRAI

\section{Background}

Delays in discharge from acute hospitals are a critical challenge for many health care systems in industrialized nations. These delayed discharges are hospital episodes where a patient exceeds the length of stay deemed medically necessary. They are commonly associated with,

\footnotetext{
* Correspondence: acosta@uwaterloo.ca

'School of Public Health and Health Systems, University of Waterloo, 200 University Avenue West, Waterloo, ON N2L 3G1, Canada

${ }^{2}$ Hamilton Niagara Haldimand Brant Community Care Access Centre (HNHB (CAC), 310 Limeridge Road West, Hamilton, ON L9C 2V2, Canada
}

though not exclusive to, older adults [1-3]. Delayed discharges represent a minority of hospital cases, yet they often have a substantial influence on patient flow throughout the hospital. This influence includes emergency department crowding (access block), cancelations of day procedures, and poor coordination of sub-acute and community care resources [4,5]. Mounting delays and their influence on overall health system capacity has lead to public pressure and targeted policy activity [1,6-11]. Although delayed discharges have a negative influence on

\section{Ciomed Central}


the health care system, they are best understood as a reflection of the underlying mismatch between the needs of patients and their access to appropriate health care services [12-14]. Patients who experience a delayed discharge are at increased risk of accelerated functional decline, social isolation, as well as the loss of independence [15-20]. Above all, delayed discharges are a reflection of health system quality.

A widely accepted, valid, and reliable definition for delayed discharge is lacking. As a result, population-level data are scarce and large investigations are rare. In Canada, acute patients with a delayed discharge are commonly referred to as "alternate level of care" (ALC) patients. The ALC construct is also used to identify delayed discharges in some jurisdictions within the United States $[5,21,22]$. In Canadian hospitals, an authorized physician or physician delegate designates ALC status when acute care services are no longer medically necessary for the patient $[23,24]$. A patient that occupies an acute care bed for over a day whilst designated ALC is referred to as an 'ALC patient' [25-28].

ALC patients have been the targets of many Canadian provincial health care strategies, and progress has been made to characterize ALC patients using administrative and clinical data [23,26,28-30]. In Canada, the distribution of bed days among ALC patients is positively skewed [28]. This suggests that the majority of ALC patients experience short delays stemming from inefficiencies, while a minority of patients experience long delays due to inadequate resources elsewhere in the health care system. A patient sub-population could be highly associated with the presence of ALC days, but if the magnitude of those days is not excessive then they will not account for a substantial portion of hospital bed inefficiency. Any characteristic (organizational or individual) that is found to influence ALC status needs to be understood in terms of its relationship to total ALC bed days in order to comprehend the effectiveness of any conceivable intervention.

Very few studies have explored long ALC lengths of stay beyond the use of limited administrative characteristics. A Canadian analysis showed that patient demographic factors are not associated with ALC length of stay [29]. Two Canadian studies suggest that patients waiting for nursing home admission (residential care) account for a large portion of ALC bed days [28,31]. Similar results have been found in other jurisdictions $[5,32,33]$. A comprehensive study that explored Canadian ALC patients waiting for nursing home admission found that some of these patients could be discharged to a community setting with the support of transitional programs and increased community care. The study concluded that no single strategy would likely meet the needs of all ALC patients waiting for nursing home admission [26]. The number of ALC days as well as the proportion of total ALC days need to be examined to understand which patients have the longest stays and account for the largest proportion of total hospital ALC bed days. Research should also establish patient characteristics that are useful for directing interventions and capacity planning [1,34]. The identification of subpopulations with excessive delays would allow for informed strategies.

The objective of this study was to identify and describe ALC patients that account for a substantial proportion of total acute hospital ALC bed days.

\section{Methods}

\section{Design and setting}

A retrospective cohort study was done using all acute hospital discharges occurring from April $1^{\text {st }} 2009$ to March $31^{\text {st }} 2011$ within a large health region in southern Ontario, Canada. The health region included over 1.3 million people, accounting for roughly $11 \%$ of the provincial population, as well as the largest number of adults over the age of 65 years. This health region contained 12 municipalities with wide variations in population density (rural and urban) and socioeconomic status. The region has 10 hospital corporations - including small community, regional, and large tertiary academic centers - with 2,087 staffed acute care beds. The study determined characteristics of ALC patients that were associated with large proportions of all acute hospital ALC days. Ethics clearance was granted from the University of Waterloo Office of Research Ethics (ORE\#16597).

\section{Data sources}

A unique health region-wide business intelligence system containing data from all hospitals and the home care agency was used to access census-level hospital and home care records linked by person level identifiers. Specifically, data from the Canadian Institute for Health Information's Discharge Abstract Database (DAD) as well as the Hamilton Niagara Haldimand Brant Community Care Access Centre's Client Health Related Information System (CHRIS) and RAI-Home Care (HC) Assessment System were abstracted.

The DAD contains information on all acute hospital discharges in Ontario, and CHRIS includes information for all home care clients and nursing home admissions in the province. Finally, the region's RAI HC Assessment System contains RAI HC assessment data for all longstay home care clients and nursing home admissions. All acute care patients in Ontario waiting for a nursing home admission, and who are not expected to go home, receive the hospital version of the RAI HC assessment to initiate their nursing home application. The RAI HC assessment is a comprehensive assessment of a person's 
strengths, preferences, and needs [35,36]. Each assessment generates a set of summary scales, including: the Cognitive Performance Scale (CPS) [37,38], the Depression Rating Scale (DRS) [39-41], and the Changes in Health, End-stage Disease, and Signs and Symptoms (CHESS) Scale [42].

\section{Sample}

The sample included all 17,111 acute hospital admissions designated as alternate level of care (ALC) that were discharged between April $1^{\text {st }} 2009$ and March $31^{\text {st }}$ 2011. No exclusions were used beyond that of ALC status and discharge date. Case level hospital records were linked to home care administrative and assessment records to determine the presence and status of any nursing home application and RAI HC assessment during the inpatient hospital stay. A patient was identified as waiting for nursing home admission if there was a RAI HC assessment completed during the hospital stay linked to an active nursing home application. If more than one assessment was completed (to reflect a change in patient status) only the most up-to-date assessment was used in order to best reflect patient characteristics at time of discharge. Home care discharge information was used to refine hospital discharge information for patients who were referred to the home care agency for home care service or nursing home application.

\section{Analysis}

Analysis was performed using SAS ${ }^{\circledR}$ Version 9.2 for Windows (SAS Institute, Inc., Cary, NC). Acute care inpatients designated ALC were stratified by nursing home admission status and described using available assessment data. Confidence intervals were employed to assess the generalizability of the study findings to all acute hospital ALC patients. Statistical significance is imputed where confidence intervals do not overlap. All confidence intervals were calculated at the $99 \%$ level (alpha $=0.01)$ and those listed for proportions were based on binomial estimation of the standard error of a proportion.

\section{Results}

Patients designated alternate level of care (ALC) and discharged between April $1^{\text {st }} 2009$ and April $1^{\text {st }} 2011$ had a mean age of 77.1 years, where $15.5 \%$ were under age 50 and $0.2 \%$ were under age 20 . The majority of ALC patients $(57.7 \%)$ were female. ALC patients waiting for nursing home admission between April $1^{\text {st }} 2009$ and April $1^{\text {st }} 2011$ had a mean age of 81.2 years, where $7.4 \%$ were under the age of $65,1.1 \%$ were under the age of 50 , and none were under 30 years old. Here too, the majority $(57.6 \%)$ were female. The mean time to nursing home (RAI HC) assessment from acute admission was 58.1 days, and the mean absolute time to nursing home (RAI HC) assessment was 39.9 days from the ALC designation. As shown in Table 1, ALC patients waiting for nursing home admission accounted for a substantial portion of all ALC bed days (41.5\%) despite accounting for a small proportion of ALC patients (8.8\%). ALC patients waiting for nursing home admission had longer acute lengths of stay (mean: 20.8, median: 13 days) and substantially longer ALC length of stay (mean: 82 days, median: 50 days).

Figure 1 shows that ADL and cognitive impairment were common among ALC patients waiting for nursing home admission - occurring in 50\% or more persons. Similarly, the high prevalence of solitary dwelling as well as caregiver distress suggested that many ALC patients waiting for nursing home admission had low informal care capacity. Mood, behavior problems, as well as psychiatric conditions were present in $12 \%$ to $25 \%$ of persons. The use of psychotropic medication was noted in $65 \%$ of ALC patients waiting for nursing home admission. Alzheimer's disease and related dementias were common, but other neurological conditions were rare. Those with morbid obesity, no informal care, as well as being at the high and low end of the age distribution were relatively rare.

ALC patients waiting for a nursing home admission had a mean ALC length of stay of 82 days. Figure 2 gives the mean deviation (from 82 days) among those ALC patients awaiting nursing home admission, by the characteristics shown in Figure 1. Those less than age 65 years, morbidly obese, with a psychiatric diagnosis, abusive behaviours, aged 65-74 years, stroke, male, as well as receiving of anxiolytics, antidepressants, and antipsychotics had significantly longer ALC lengths of stay. Characteristics significantly associated with shorter

Table 1 Total acute hospital ALC days among ALC patients waiting for nursing home admission, fiscal 2010-2011

\begin{tabular}{|c|c|c|c|c|c|c|}
\hline \multirow[t]{2}{*}{ Sub-Group } & \multicolumn{2}{|c|}{$\begin{array}{l}\text { Proportion of all } \\
\text { ALC patients }\end{array}$} & \multirow{2}{*}{$\begin{array}{l}\text { Mean Acute } \\
\text { Length of Stay } \\
\text { Days (CI) }\end{array}$} & \multirow{2}{*}{$\begin{array}{l}\text { Mean ALC } \\
\text { Length of Stay } \\
\text { Days }(C I)\end{array}$} & \multicolumn{2}{|c|}{$\begin{array}{l}\text { Proportion of } \\
\text { all ALC days }\end{array}$} \\
\hline & $\%(C I)$ & $N$ & & & $\%(C I)$ & $N$ \\
\hline ALC patients waiting for nursing home placement ${ }^{*}$ & $8.8( \pm 0.5)$ & 1488 & $20.8( \pm 0.9)$ & $82.0( \pm 2.4)$ & $41.5( \pm 0.2)$ & 122090 \\
\hline $\begin{array}{l}\text { All other ALC patients (not waiting for nursing } \\
\text { home placement) }\end{array}$ & $91.2( \pm 0.6)$ & 15623 & $11.7( \pm 0.5)$ & $10.5( \pm 1.6)$ & $58.5( \pm 0.2)$ & 172108 \\
\hline
\end{tabular}

Note: All confidence intervals are $99 \%$ (alpha $=0.01$ ) unless otherwise specified.

*Having an accepted nursing home referral as well as a completed RAI Home Care assessment with the nursing home application. 


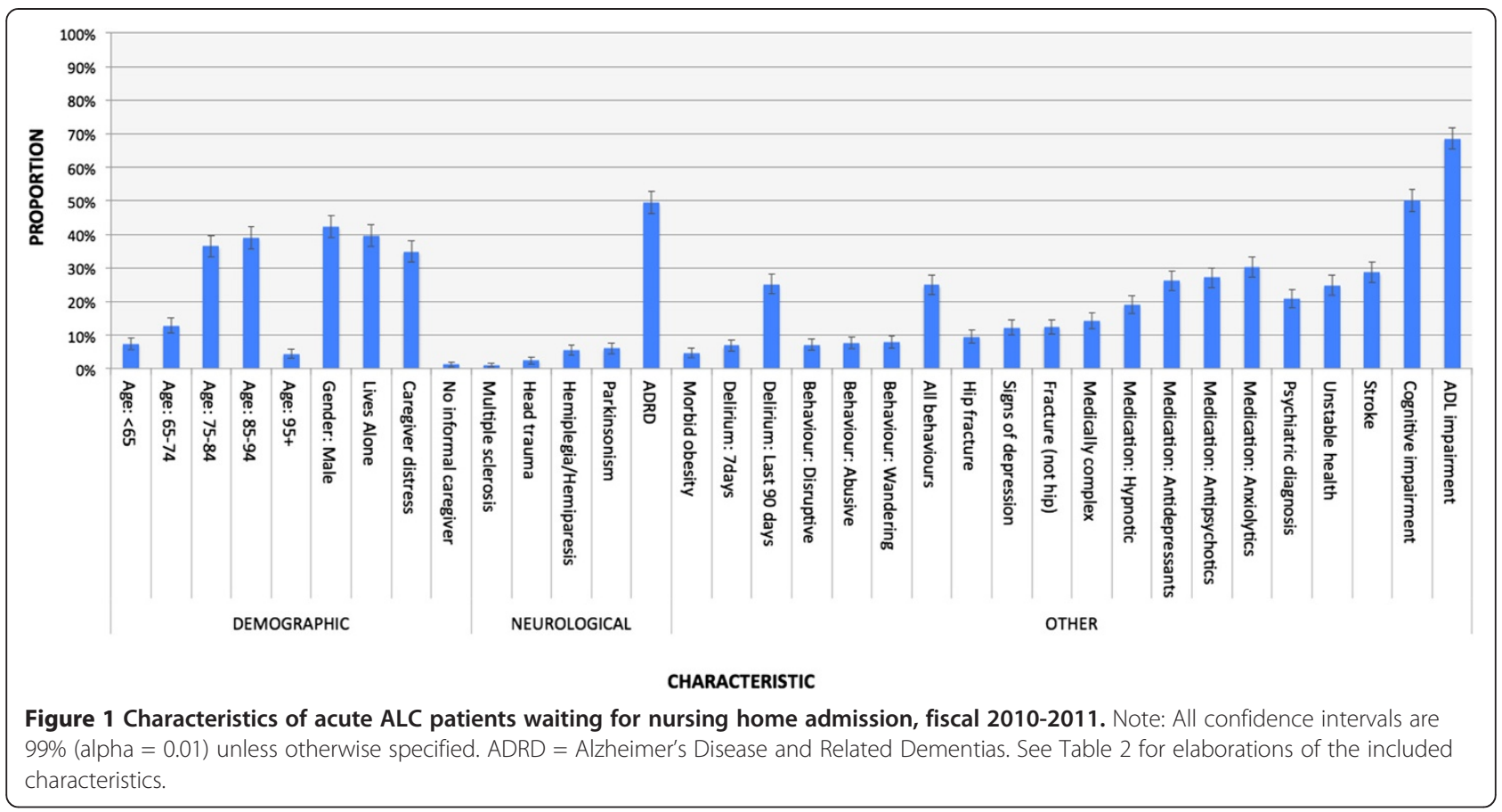

ALC lengths of stay were delirium (during last 7 days or 90 days), unstable health, head trauma, having no source of informal care, being aged 85-95, medically complex, as well as caregiver distress. With exception to head trauma, none of the neurological conditions collected were significantly associated with higher or lower ALC length of stay relative to the mean. Many characteristics show very little influence on acute ALC length of stay or have no significant influence.

All characteristics that were significantly associated with ALC length of stay were subjected to a linear regression analysis to identify independent effects. Figure 3

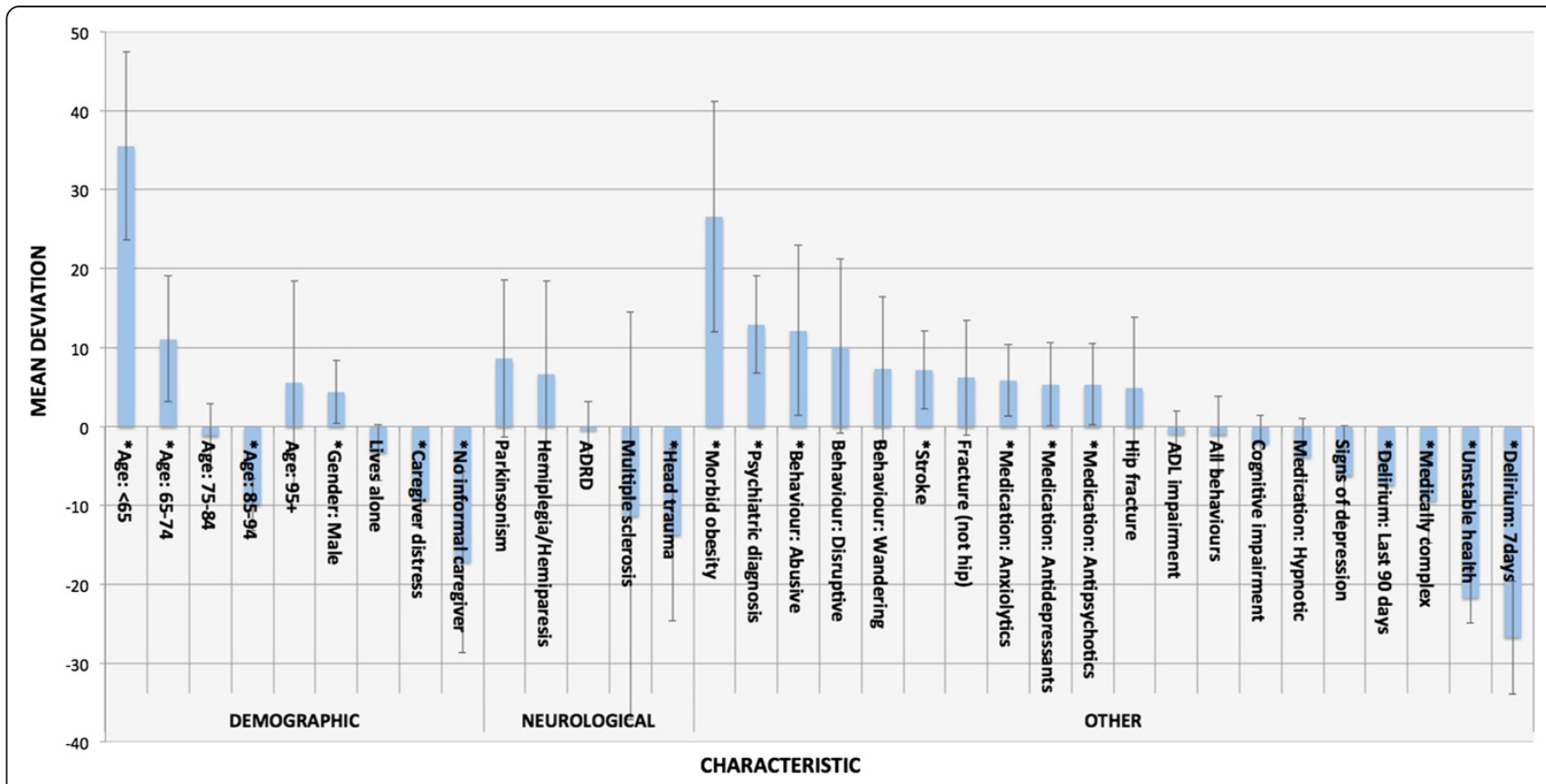

Figure 2 Mean deviation in ALC length of stay by patient characteristics, ALC patients waiting for nursing home admission, fiscal 2010-2011. Note: All confidence intervals are 99\% (alpha =0.01) unless otherwise specified. *Significant effect. ADRD = Alzheimer's Disease and Related Dementias. See Table 2 for elaborations of the included characteristics. 


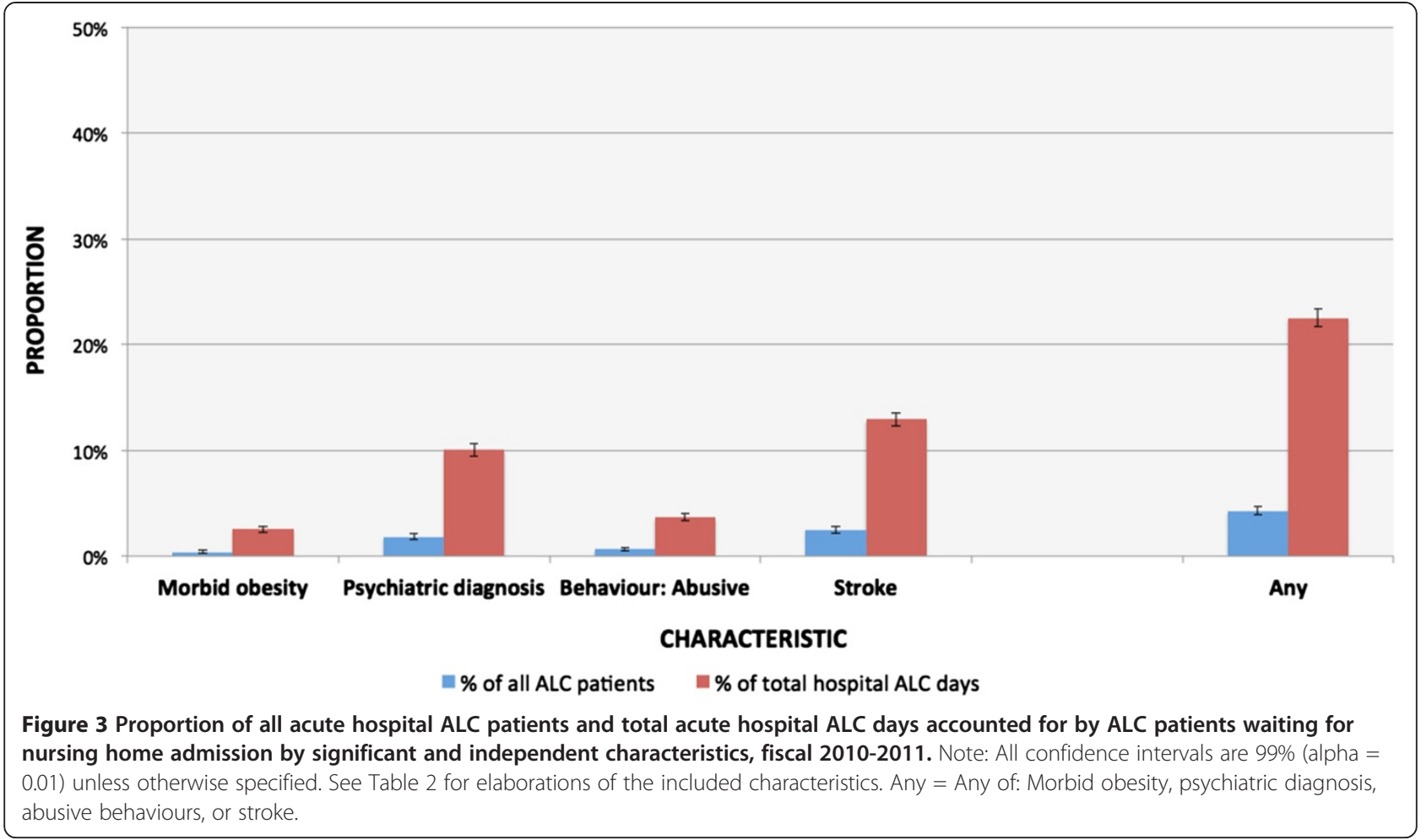

shows the independent groups with significant associations found in Figure 2. Morbid obesity, psychiatric diagnosis, abusive behaviors, and stroke represent near exclusive groups that were highly correlated with demographic characteristics and the provision of psychotropic medication. Overall, persons with morbid obesity, a psychiatric diagnosis, abusive behaviors, or stroke accounted for $4.3 \%$ of all patients designated ALC and $23 \%$ of total acute hospital ALC days between April $1^{\text {st }} 2009$ and April $1^{\text {st }}, 2011$.

Table 2 gives the clinical profiles for acute ALC patients with characteristics that were significantly associated with longer ALC lengths of stay. Groups shown in Table 2 were not significantly correlated (also evidenced by a comparison of the proportions) and represent independent effects. ALC patients waiting for nursing home admission that were morbidly obese were younger and more likely to have previously resided in a nursing home. They were more likely to have physical impairments and to be medically complex but less likely to have cognitive conditions. Behaviors and use of psychotropic medication were less common relative to all ALC patients waiting for admission. Those with a stroke diagnosis had characteristics that were very similar to all ALC patients waiting for nursing home admission. ALC patients waiting for nursing home admission with a psychiatric diagnosis were younger and more likely to have received psychotropic medication. Those with abusive behaviours were more likely to be male, have caregiver distress, cognitive/neurological conditions, communication difficulty, other behaviours, as well as more likely to have received antipsychotic and hypnotic medication. All groups had similar discharge destinations, where the majority were discharged to a complex continuing care facility to continue to wait for nursing home admission. Roughly equal proportions were discharged directly to nursing home or to their homes with formal home care supports.

\section{Discussion}

Acute ALC patients waiting for nursing home admission contribute approximately four times as many inappropriate bed days relative to their proportion. In particular, those with morbid obesity, abusive behaviors as well as a diagnosis of stroke or psychiatric condition account for a greater proportion of total acute hospital ALC days. In Canada, attention should focus on the ALC patient subpopulations identified in this investigation to identify potential solutions for delayed discharges.

The finding that increased non-medical days was associated with waiting for nursing home admission has been reported elsewhere [5,28,31-33]. Other studies have found increased non-medical days among acute inpatients to be associated with stroke $[13,23,31,44,45]$, neurological conditions, and psychiatric disorders [23,46-48]. Also, a U.S. study found that behaviors were predictive of delayed discharges [49], but no investigation has identified the particular behaviors that drive the effect. ALC patients that exhibited abusive behaviors had 
Table 2 Profiles of clinical sub-groups with significantly longer ALC stays, ALC patients waiting for nursing home admission, fiscal 2010-2011

\begin{tabular}{|c|c|c|c|c|c|c|c|c|}
\hline & \multicolumn{2}{|c|}{ Morbid Obesity $(\mathrm{N}=69)$} & \multicolumn{2}{|c|}{ Stroke $(\mathrm{N}=426)$} & \multicolumn{2}{|c|}{ Psychiatric Diagnosis $(\mathrm{N}=311)$} & \multicolumn{2}{|c|}{ Abusive Behaviours $(\mathrm{N}=115)$} \\
\hline & $\%(\mathrm{Cl})$ & $\mathbf{N}$ & $\%(\mathrm{Cl})$ & $\mathrm{N}$ & $\%(\mathrm{Cl})$ & $\mathrm{N}$ & $\%(\mathrm{Cl})$ & $\mathrm{N}$ \\
\hline \multicolumn{9}{|l|}{ Demographic Characteristics } \\
\hline Age (mean) & $75.2( \pm 1.3)$ & 69 & $80.0( \pm 0.5)$ & 426 & $76.3( \pm 0.7)$ & 311 & $81.8( \pm 0.8)$ & 115 \\
\hline \multicolumn{9}{|l|}{ Age } \\
\hline$<65$ & $15.9( \pm 11.3)$ & 11 & $9.2( \pm 3.6)$ & 39 & $17.4( \pm 5.5)$ & 54 & $6.1( \pm 5.7)$ & 7 \\
\hline $65-74$ & $21.7( \pm 12.8)$ & 15 & $15.0( \pm 4.5)$ & 64 & $16.7( \pm 5.5)$ & 52 & $13.9( \pm 8.3)$ & 16 \\
\hline $75-84$ & $43.5( \pm 15.4)$ & 30 & $39.0( \pm 6.1)$ & 166 & $39.6( \pm 7.1)$ & 123 & $33.0( \pm 11.3)$ & 38 \\
\hline $85-94$ & $18.8( \pm 12.1)$ & 13 & $34.0( \pm 5.9)$ & 145 & $24.1( \pm 6.2)$ & 75 & $43.5( \pm 11.9)$ & 50 \\
\hline$\geq 95$ & $0.0( \pm 0.0)$ & 0 & $2.8( \pm 2.1)$ & 12 & $2.3( \pm 2.2)$ & 7 & $3.5( \pm 3.5)$ & 4 \\
\hline \multicolumn{9}{|l|}{ Gender } \\
\hline Male & $31.9( \pm 1.9)$ & 22 & $46.9( \pm 0.9)$ & 200 & $38.9( \pm 0.9)$ & 121 & $58.2( \pm 1.8)$ & 67 \\
\hline Lived alone & $29.0( \pm 14.1)$ & 20 & $36.2( \pm 6.0)$ & 154 & $38.9( \pm 7.1)$ & 121 & $33.0( \pm 11.3)$ & 38 \\
\hline \multicolumn{9}{|l|}{ Lived in } \\
\hline Private residence & $33.3( \pm 14.6)$ & 23 & $57.5( \pm 6.2)$ & 245 & $46.6( \pm 7.3)$ & 145 & $61.7( \pm 11.7)$ & 71 \\
\hline Private residence $\left(\mathrm{HC}^{\S}\right)$ & $42.0( \pm 15.3)$ & 29 & $29.3( \pm 5.7)$ & 125 & $29.9( \pm 6.7)$ & 93 & $27.0( \pm 10.7)$ & 31 \\
\hline Board/assisted/group home & $8.7( \pm 8.7)$ & 6 & $8.2( \pm 3.4)$ & 35 & $13.8( \pm 5.0)$ & 43 & $7.0( \pm 6.1)$ & 8 \\
\hline Residential Care & $13.0( \pm 10.4)$ & 9 & $3.3( \pm 2.2)$ & 14 & $5.8( \pm 3.4)$ & 18 & $2.6( \pm 2.6)$ & 3 \\
\hline Other & $2.9( \pm 2.9)$ & 2 & $1.6( \pm 1.6)$ & 7 & $3.9( \pm 2.8)$ & 12 & $1.7( \pm 1.7)$ & 2 \\
\hline \multicolumn{9}{|l|}{ Primary Caregiver Status } \\
\hline No Caregiver & $1.5( \pm 1.5)$ & 1 & $1.2( \pm 1.2)$ & 5 & $2.3( \pm 2.2)$ & 7 & $2.6( \pm 2.6)$ & 3 \\
\hline Caregiver lived with client & $56.5( \pm 15.4)$ & 39 & $56.6( \pm 6.2)$ & 241 & $66.9( \pm 6.9)$ & 208 & $58.3( \pm 11.8)$ & 67 \\
\hline Caregiver is a spouse & $29.0( \pm 14.1)$ & 20 & $27.5( \pm 5.6)$ & 117 & $21.5( \pm 6.0)$ & 67 & $34.8( \pm 11.4)$ & 40 \\
\hline Is a child or child-in-law & $49.3( \pm 15.5)$ & 34 & $54.7( \pm 6.2)$ & 233 & $51.5( \pm 7.3)$ & 160 & $44.4( \pm 11.9)$ & 51 \\
\hline Caregiver distress $^{1}$ & $30.4( \pm 14.3)$ & 21 & $35.0( \pm 6.0)$ & 149 & $32.5( \pm 6.8)$ & 101 & $56.5( \pm 11.9)$ & 65 \\
\hline \multicolumn{9}{|l|}{ Clinical Characteristics } \\
\hline Cognitive Impairment $^{2}$ & $31.9( \pm 14.5)$ & 22 & $57.0( \pm 6.2)$ & 243 & $48.2( \pm 7.3)$ & 150 & $81.7( \pm 9.3)$ & 94 \\
\hline \multicolumn{9}{|l|}{ Potential Delirium } \\
\hline Last 7 days $^{3}$ & $4.4( \pm 4.4)$ & 3 & $5.9( \pm 2.9)$ & 25 & $7.1( \pm 3.7)$ & 22 & $17.4( \pm 9.1)$ & 20 \\
\hline Last 90 days ${ }^{4}$ & $8.7( \pm 8.7)$ & 6 & $26.8( \pm 5.5)$ & 114 & $24.1( \pm 6.2)$ & 75 & $48.7( \pm 12.0)$ & 56 \\
\hline ADL Impairment ${ }^{5}$ & $82.6( \pm 11.8)$ & 57 & $75.8( \pm 5.3)$ & 323 & $67.2( \pm 6.9)$ & 209 & $73.9( \pm 10.5)$ & 85 \\
\hline \multicolumn{9}{|l|}{ Communication } \\
\hline Difficulty making self understood & $17.4( \pm 11.8)$ & 12 & $44.2( \pm 6.2)$ & 188 & $32.8( \pm 6.9)$ & 102 & $54.8( \pm 12.0)$ & 63 \\
\hline Difficulty understanding others & $23.2( \pm 13.1)$ & 16 & $42.7( \pm 6.2)$ & 182 & $35.7( \pm 7.0)$ & 111 & $61.7( \pm 11.7)$ & 71 \\
\hline \multicolumn{9}{|l|}{ Behaviours $^{6}$} \\
\hline Any $^{7}$ & $14.5( \pm 10.9)$ & 10 & $25.6( \pm 5.4)$ & 109 & $28.9( \pm 6.6)$ & 90 & $100.0( \pm 0.0)$ & 115 \\
\hline Abusive & $2.9( \pm 2.9)$ & 2 & $8.2( \pm 3.4)$ & 35 & $8.7( \pm 4.1)$ & 27 & $100.0( \pm 0.0)$ & 115 \\
\hline Disruptive & $4.4( \pm 4.4)$ & 3 & $5.4( \pm 2.8)$ & 23 & $9.3( \pm 4.2)$ & 29 & $30.4( \pm 11.1)$ & 35 \\
\hline Wandering & $2.9( \pm 2.9)$ & 2 & $7.5( \pm 3.3)$ & 32 & $5.8( \pm 3.4)$ & 18 & $31.3( \pm 11.1)$ & 36 \\
\hline Psychiatric Diagnosis $^{8}$ & $27.5( \pm 13.9)$ & 19 & $23.9( \pm 5.3)$ & 102 & $100.0( \pm 0.0)$ & 311 & $23.5( \pm 10.2)$ & 27 \\
\hline \multicolumn{9}{|l|}{ Psychotropic Medications $^{8}$} \\
\hline Anxiolytics & $47.8( \pm 15.5)$ & 33 & $33.6( \pm 5.9)$ & 143 & $64.3( \pm 7.0)$ & 200 & $35.7( \pm 11.5)$ & 41 \\
\hline Antidepressants & $23.2( \pm 13.1)$ & 16 & $23.7( \pm 5.3)$ & 101 & $37.3( \pm 7.1)$ & 116 & $29.6( \pm 11.0)$ & 34 \\
\hline Antipsychotics & $10.1( \pm 9.4)$ & 7 & $26.1( \pm 5.5)$ & 111 & $40.8( \pm 7.2)$ & 127 & $55.7( \pm 11.9)$ & 64 \\
\hline Hypnotic & $15.9( \pm 11.4)$ & 11 & $17.1( \pm 4.7)$ & 73 & $27.0( \pm 6.5)$ & 84 & $28.7( \pm 10.9)$ & 33 \\
\hline
\end{tabular}


Table 2 Profiles of clinical sub-groups with significantly longer ALC stays, ALC patients waiting for nursing home admission, fiscal 2010-2011 (Continued)

\begin{tabular}{|c|c|c|c|c|c|c|c|c|}
\hline Fractures $^{\mathbf{8}}$ & & & & & & & & \\
\hline Hip & $5.8( \pm 5.8)$ & 4 & $9.2( \pm 3.6)$ & 39 & $10.0( \pm 4.4)$ & 31 & $13.0( \pm 8.1)$ & 15 \\
\hline Other & $7.3( \pm 7.3)$ & 5 & $11.0( \pm 3.9)$ & 47 & $15.4( \pm 5.3)$ & 48 & $10.4( \pm 7.3)$ & 12 \\
\hline Stroke ${ }^{8}$ & $29.0( \pm 14.1)$ & 20 & $100.0( \pm 0.0)$ & 426 & $32.8( \pm 6.9)$ & 102 & $30.4( \pm 11.1)$ & 35 \\
\hline Morbid Obesity & $100.0( \pm 0.0)$ & 69 & $4.7( \pm 2.6)$ & 20 & $6.1( \pm 3.5)$ & 19 & $1.7( \pm 1.7)$ & 2 \\
\hline Medically Complex ${ }^{9}$ & $24.6( \pm 13.4)$ & 17 & $12.2( \pm 4.1)$ & 52 & $13.2( \pm 4.9)$ & 41 & $8.7( \pm 6.8)$ & 10 \\
\hline Unstable Health ${ }^{10}$ & $33.3( \pm 14.6)$ & 23 & $22.3( \pm 5.2)$ & 95 & $21.9( \pm 6.0)$ & 68 & $36.5( \pm 11.6)$ & 42 \\
\hline Neurological Conditions & & & & & & & & \\
\hline $\mathrm{ADRD}^{11}$ & $24.6( \pm 13.4)$ & 17 & $46.2( \pm 6.2)$ & 197 & $44.4( \pm 7.3)$ & 138 & $73.9( \pm 10.5)$ & 85 \\
\hline Head trauma & $1.5( \pm 1.5)$ & 1 & $2.8( \pm 2.1)$ & 12 & $4.2( \pm 2.9)$ & 13 & $7.8( \pm 6.5)$ & 9 \\
\hline Hemiplegia/Hemiparesis & $5.8( \pm 5.8)$ & 4 & $15.3( \pm 4.5)$ & 65 & $5.5( \pm 3.3)$ & 17 & $3.5( \pm 3.5)$ & 4 \\
\hline Multiple sclerosis & $2.9( \pm 2.9)$ & 2 & $0.5( \pm 0.5)$ & 2 & $1.6( \pm 1.6)$ & 5 & $0.0( \pm 0.0)$ & 0 \\
\hline Parkinsonism & $7.3( \pm 7.3)$ & 5 & $4.5( \pm 2.6)$ & 19 & $7.7( \pm 3.9)$ & 24 & $7.0( \pm 6.1)$ & 8 \\
\hline Discharge Destination & & & & & & & & \\
\hline Residential care & $15.9( \pm 11.4)$ & 11 & $17.4( \pm 4.7)$ & 74 & $14.5( \pm 5.1)$ & 45 & $20.0( \pm 9.6)$ & 23 \\
\hline Home (with Home Care Services) & $23.2( \pm 13.2)$ & 16 & $11.9( \pm 4.0)$ & 51 & $13.8( \pm 5.0)$ & 43 & $13.9( \pm 8.3)$ & 16 \\
\hline Transfers & & & & & & & & \\
\hline Complex Care (waiting for placement) & $57.9( \pm 15.3)$ & 40 & $66.9( \pm 5.9)$ & 285 & $65.6( \pm 6.9)$ & 204 & $58.2( \pm 11.9)$ & 67 \\
\hline Other & $1.5( \pm 1.5)$ & 1 & $0.5( \pm 0.5)$ & 2 & $1.3( \pm 1.3)$ & 4 & $0.9( \pm 0.9)$ & 1 \\
\hline Died & $1.5( \pm 1.5)$ & 1 & $2.8( \pm 2.1)$ & 12 & $3.9( \pm 2.8)$ & 12 & $5.2( \pm 5.2)$ & 6 \\
\hline Other & $0.0( \pm 0.0)$ & 0 & $0.5( \pm 0.5)$ & 2 & $1.0( \pm 1.0)$ & 3 & $1.7( \pm 1.7)$ & 2 \\
\hline
\end{tabular}

Note: All confidence intervals are $99 \%$ (alpha $=0.01$ ) unless otherwise specified.

$\$$ ' $\mathrm{HC}$ ' = Home Care.

${ }^{1}$ Primary caregiver expresses feelings of distress, anger or depression.

${ }^{2}$ Based on the interRAI Cognitive Performance Scale (CPS) levels $\geq 3$. Equivalent to 15 - 1 MMSE [37,38].

${ }^{3}$ Sudden or new onset/change in mental function over last 7 days (from assessment date).

${ }^{4}$ In last 90 days (from assessment date) person has become agitated/disoriented such that their safety is endangered or requires protection.

${ }^{5}$ Based on the interRAI ADL Hierarchy Scale levels $\geq 3$ [43].

${ }^{6}$ Any such occurrence in the last 3 days.

${ }^{7}$ Any of: Abusive (physically or verbally), Disruptive (incl. Socially inappropriate), wandering, and resisting care.

${ }^{8}$ Doctor has indicated is present and affects patients status, requires treatment, or symptom management.

${ }^{9}$ Any receipt of the following in the last 7 days: respiratory treatments, haemodialysis, or tracheotomy care.

${ }^{10}$ Based on the interRAI Changes in Health, End-stage Disease, and Signs and Symptoms (CHESS) Scale [42], levels $\geq 3$.

${ }^{11}$ ADRD = Alzheimer's Disease and Related Dementias.

significantly more ALC bed days relative to the average. Morbid obesity was significantly associated with longer delays among ALC patients waiting for nursing home admission. Obesity has not been explored in previous investigations, likely due to the lack of relevant data in hospital records. Cognitive impairment and informal care capacity were common conditions among all ALC patients waiting for nursing home admission and have been linked to the presence of non-medical days in other investigations $[2,23,33,48,50]$. Demographic characteristics and particular classes of psychotropic medications were significantly associated with longer ALC lengths as well as highly correlated with the identified clinical subpopulations. Significant increases in ALC length of stay for the identified clinical sub-groups reflect the difficulty in arranging nursing home placement for persons that require unique care equipment and considerable care resources.
ALC patients with signs of potential delirium, informal care distress, head trauma, unstable health, and medical complexity had significantly fewer ALC bed days relative to other ALC patients waiting for admission. ALC patients with potential delirium may have better prospects for nursing home admission if their cognitive status improved. Likewise, those with medical complexity and unstable health may have improved prospects for an immediate nursing home admission if their health status stabilized. The likelihood for improvement of acute medical issues is high, relative to geriatric syndromes, given the skill mix in many acute care settings. The finding that those with caregiver distress were negatively associated with increased ALC bed days could relate an increased likelihood of informal caregivers to accept non-optimal placements as a result of strain and stress. None of these hypotheses could have been addressed in this study and require more investigation. 
The province of Ontario has approximately 70,000 publicly funded nursing home beds [51] and approximately 1.6 million citizens over the age of 65 [52]. This investigation suggests that acute care patients with the highest needs experience greater barriers in the nursing home admission process. This finding is similar to the an Australian simulation study that found that the acute hospital sector acts as a safety net for persons who cannot find appropriate placement in a nursing home [53]. The inherent problem in this situation is that those with the most potential for transition to community-based care are those that are admitted to nursing homes, whereas those with the least potential for returning to communitybased care remain in the acute hospital. Although a reflexive response to this problem may be to increase supply of nursing home beds, a more careful exploration of other possible alternatives is required. Without alternatives, the demand for nursing home beds will almost certainly continue to be greater than the capacity of that sector. A recent provincial report suggests that nursing home capacity would need to increase by $75 \%$ over the next decade to meet the projected demand [30].

A more sustainable strategy to increasing nursing home bed supply will likely involve better management of existing nursing home bed capacity. Specifically, there should be incentives for nursing homes to admit high needs patients from acute care. This change in incentive would require a sustained increase in funding to ensure that nursing home staff have the necessary skill sets, and it may also require facility redesign to sustain quality of life and quality of care. This investigation suggests that the capacity to address weight, neurological, psychological, and behavioral conditions is underrepresented in nursing homes and should be the focus for increasing nursing home capacity. A funding formula that considers resident case mix would be an essential tool for eliminating disincentives to admit acute patients with complex needs. Additional incentives could be considered [54], and some of this may be supported through a reallocation of funding from sectors with cost reductions (i.e., hospitals) to those with increased costs associated with caring for more complex populations (i.e., home care and nursing homes).

Many older adults have negative views of nursing home settings. As such, nursing homes should be considered as the option of last resort rather than a default destination. Community and congregate living arrangements, though preferred, are unlikely living arrangements for many of those with significantly longer non-medical days. However, lighter care acute care patients can be considered for transitional care programs that will allow them to live in a community or congregate living arrangement. Such living options also need to be available for older adults who are discharged from acute hospitals but are no longer able to live independently.
Ultimately, improved resources and coordination are needed in acute hospitals to address the pattern of increasing dependence that then leads to decreasing discharge potential. Evidence suggests that older adults admitted to acute medical units deteriorate as well as acquire new geriatric syndromes [55]. Elder friendly ALC units have been described in the literature [21]. These units have structural changes are designed to increase socialization, improve orientation, and decrease barriers to locomotion. These units also feature staff reorganization where acute nursing is reduced and personal supports as well as allied health professionals are increased. Such units are have been found to reduce staff injury [56,57]. Likewise, the use of rehabilitation has been shown to reduce delayed discharge rates [58]. A U. S. study found that early and continuous discharge planning reduced ALC days [5]. Evidence suggests that discharge planning should commence at admission and reflect the changing status of a patient such that their discharge potential improves as independence is maintained or improved. Hospitals expend valuable staff resources reacting to bed supply crises and may be better served by a focus on early discharge planning [8]. This investigation also identified the need for psychogeriatric services or psychiatric consult services within elder friendly acute units. Case finding tools in the emergency department show promise to stream acute medical admissions into early case management programs or divert directly into post-acute restorative/transitional programs [59].

\section{Limitations}

Given that the assessment data captured in this study did not necessarily reflect the characteristics of ALC patients at time of admission to a nursing home or at ALC designation, the characteristics presented cannot be assumed to be predictive of excessive non-medical lengths of stay. The results of this study do not reflect the characteristics of ALC patients that were not in application to a nursing home. Further, given that this study examined records from a particular health region during a particular time period, the results may not be generalizable to all jurisdictions. Persons comparing these data to data available through other reporting systems should note that data from discharged records do not necessary reflect data from real time reporting systems given that ALC days are accrued on discharge.

\section{Conclusions}

This study suggests that a minority of persons with any non-medical acute care days contribute to a substantial proportion of total non-medical days in acute hospitals. Patients waiting for nursing home admission accounted for a substantial portion of non-medical bed days. Those 
with morbid obesity, abusive behaviors as well as a diagnosis of stroke or psychiatric condition are particularly important sub-population for capacity planning and improved coordination within the health care system.

\section{Competing interests}

The authors declare that they have no competing interests.

\section{Acknowledgements}

The authors gratefully acknowledge the Hamilton Niagara Haldimand Brant Local Health Integration Network (HNHB LHIN) Integrated Decision Support Project Team for allowing access to the study data. APC is supported by a Canadian Institute of Health Research (CIHR) Frederick Banting and Charles Best Canada Doctoral Scholarship. Partial funding for this publication was also provided by the Public Health Agency of Canada. JPH is supported by a Home Care grant from the Ontario Ministry of Health and Long Term Care (MOHLTC) as well as Neurological grant from CIHR. The opinions and conclusions expressed in this article are those of the authors and do not necessarily reflect the views of the HNHB LHIN, CIHR, Ontario MOHLTC, or the Public Health Agency of Canada.

\section{Authors' contributions}

APC proposed the study, completed the data analysis and prepared the manuscript as well as the revisions of the manuscript. JWP reviewed the analysis, and participated in the revisions of the manuscript. TP and JPH participated in the interpretation of the data and in the discussion of the results. All authors read and approved the final manuscript. APC takes responsibility for the paper.

Received: 22 March 2012 Accepted: 22 June 2012

Published: 22 June 2012

\section{References}

1. Lim SC, Doshi V, Castasus B, Lim JK, Mamun K: Factors causing delay in discharge of elderly patients in an acute care hospital. Ann Acad Med Singapore 2006, 35:27-32.

2. Rockwood K: Delays in the discharge of elderly patients. J Clin Epidemiol 1990, 43:971-975.

3. Victor CR: A survey of the delayed discharge of elderly people from hospitals in an inner-London health district. Arch Gerontol Geriatr 1990, 10:199-205.

4. ALC Expert Panel: Appropriate level of care: A patient flow, system integration and capacity solution. Toronto: Ministry of Health and Long-Term Care; 2006.

5. Rock BD, Beckerman A, Auerbach C, Cohen C, Goldstein M, Quitkin E: Management of alternate level of care patients using a computerized database. Health Soc Work 1995, 20:133-139.

6. Abe Y, Ai M, Kaneko M, Sawara M, Nagano K, Shimokado K: Studies on factors related to delayed discharge of elderly patients from university hospitals. Nippon Ronen Igakkai Zasshi 2007, 44:641-647.

7. Baumann M, Evans S, Perkins M, Curtis L, Netten A, Fernandez JL, Huxley P: Organisation and features of hospital, intermediate care and social services in English sites with low rates of delayed discharge. Health Soc Care Community 2007, 15:295-305.

8. Black D, Pearson M: Average length of stay, delayed discharge, and hospital congestion. BMJ 2002, 325:610-611.

9. Epstein J, Kaplan G, Lavi B, Noy S, Ben Shahar I, Shahaf P, Stanger V, Rotstein $Z$ : A description of inappropriate hospital stays in selected in-patient services: a study of cases receiving social work services. Soc Work Health Care 2001, 32:43-65.

10. Rae B, Busby W, Millard PH: Fast-tracking acute hospital care-from bed crisis to bed crisis. Aust Health Rev 2007, 31:50-62.

11. Scott H: Elderly patients: people not 'bed-blockers'. Br J Nurs 2000, 9:528.

12. Coid J, Crome P: Bed blocking in Bromley. Br Med J (Clin Res Ed) 1986, 292:1253-1256.

13. Lewis H, Purdie G: The blocked bed: a prospective study. N Z Med J 1988, 101:575-577.

14. Thamprechavai S, Somerville K, Jitapunkul S, Bunnag S, Ebrahim S: Elderly bed-blockers in a Thai teaching hospital: is it a problem? J Med Assoc Thai 1992, 75:418-422.
15. Covinsky KE, Palmer RM, Fortinsky RH, Counsell SR, Stewart AL, Kresevic D, Burant CJ, Landefeld CS: Loss of independence in activities of daily living in older adults hospitalized with medical illnesses: increased vulnerability with age. J Am Geriatr Soc 2003, 51:451-458.

16. Creditor MC: Hazards of hospitalization of the elderly. Ann Intern Med 1993, 118:219-223.

17. Fortinsky RH, Covinsky KE, Palmer RM, Landefeld CS: Effects of functional status changes before and during hospitalization on nursing home admission of older adults. J Gerontol A Biol Sci Med Sci 1999, 54:M521-M526.

18. Graf C: Functional decline in hospitalized older adults. Am J Nurs 2006, 106:58-67. quiz 67-8.

19. Hitcho EB, Krauss MJ, Birge S, Claiborne Dunagan W, Fischer I, Johnson S, Nast PA, Costantinou E, Fraser VJ: Characteristics and circumstances of falls in a hospital setting: a prospective analysis. J Gen Intern Med 2004, 19:732-739.

20. Kydd A: The patient experience of being a delayed discharge. J Nurs Manag 2008, 16:121-126.

21. Burgin A, Schuetz MP: Establishing an alternate level of care unit. J Nurs Adm 1992, 22:62-65.

22. Tellis-Nayak V, Tellis-Nayak M: An alternate level of care, the prospective payment system and the challenge of extended care. Soc Sci Med 1986, 23:665-671.

23. Canadian Institute for Health Information: Alternate level of care in Canada. Toronto; 2009. http://secure.cihi.ca/cihiweb/dispPage.jsp? cW_page=PG_1751_E\&cw_topic $=1751 \& \mathrm{cw}$ rel=AR_2610_E\#full.

24. Alternate Level of Care. Toronto: Cancer Care Ontario; 2009. https://www.cancercare.on.ca/ocs/alc/.

25. Bruce S, DeCoster C, Trumble-Waddell J, Burchill C: Patients hospitalized for medical conditions in Winnipeg, Canada: appropriateness and level of care. Healthc Manage Forum 2002, (Winter, Suppl):53-57.

26. Costa AP, Hirdes JP: Clinical Characteristics and Service Needs of Alternate-Level-of-Care Patients Waiting for Long-Term Care in Ontario Hospitals. Healthc Policy 2010, 6:32-46.

27. Penney C, Henry E: Improving performance management for delivering appropriate care for patients no longer needing acute hospital care. J Health Serv Res Policy 2008, 13(Suppl 1):30-34.

28. Walker JD, Morris K, Frood J: Alternate Level of Care in Canada: A Summary. Healthc Q 2009, 12:21-23.

29. How Long Do Alternate Level of Care (ALC) Patients Wait? Toronto: Canadian Institute for Health Information; 2011. http://www.cihi.ca/CIHI-ext-portal/ internet/en/Document/health+system+performance/integration+and +continuity+of+care/FAQ_INT_ALC_PATIENTSWAIT.

30. Walker David, Provincial ALC Lead: Caring for our aging population and addressing alternate level of care (ALC). report submitted to the minister of health and long-term care. Toronto: Queen's Printer for Ontario; 2011.

31. Mayo NE, Wood-Dauphinee S, Gayton D, Scott SC: Nonmedical bed-days for stroke patients admitted to acute-care hospitals in Montreal, Canada. Stroke 1997, 28:543-549.

32. Gallagher P, Henry C, O'Callaghan N: Do relatives of elderly patients block the discharge process? Ir Med J 2008, 101:70-72.

33. Victor CR, Healy J, Thomas A, Seargeant J: Older patients and delayed discharge from hospital. Health Soc Care Community 2000, 8:443-452.

34. Chin JJ, Sahadevan S, Tan CY, Ho SC, Choo PW: Critical role of functional decline in delayed discharge from an acute geriatric unit. Ann Acad Med Singapore 2001, 30:593-599.

35. Morris JN, Fries BE, Steel K, Ikegami N, Bernabei R, Carpenter Gl, Gilgen R, Hirdes JP, Topinková E: Comprehensive clinical assessment in community setting: applicability of the MDS-HC. J Am Geriatr Soc 1997, 45:1017-1024.

36. Poss JW, Jutan NM, Hirdes JP, Fries BE, Morris JN, Teare GF, Reidel K: A review of evidence on the reliability and validity of Minimum Data Set data. Healthc Manage Forum 2008, 21:33-39.

37. Hartmaier SL, Sloane PD, Guess HA, Koch GG, Mitchell CM, Phillips CD: Validation of the Minimum Data Set Cognitive Performance Scale: agreement with the Mini-Mental State Examination. J Gerontol Series ABiological Sci Med Sci 1995, 50:M128-M133.

38. Morris JN, Fries BE, Mehr DR, Hawes C, Phillips C, Mor V, Lipsitz LA: MDS Cognitive Performance Scale. J Gerontol 1994, 49:M174-M182.

39. Burrows AB, Morris JN, Simon SE, Hirdes JP, Phillips C: Development of a minimum data set-based depression rating scale for use in nursing homes. Age Ageing 2000, 29:165-172. 
40. Koehler M, Rabinowitz T, Hirdes J, Stones M, Carpenter Gl, Fries BE, Morris $J N$, Jones RN: Measuring depression in nursing home residents with the MDS and GDS: an observational psychometric study. BMC Geriatr 2005, 5:1.

41. Martin L, Poss JW, Hirdes JP, Jones RN, Stones MJ, Fries BE: Predictors of a new depression diagnosis among older adults admitted to complex continuing care: implications for the depression rating scale (DRS). Age Ageing 2008, 37:51-56.

42. Hirdes JP, Frijters DH, Teare GF: The MDS-CHESS scale: a new measure to predict mortality in institutionalized older people. J Am Geriatr Soc 2003, 51:96-100.

43. Morris JN, Fries BE, Morris SA: Scaling ADLs within the MDS. Journals of Gerontology Series A-Biological Sciences \& Medical Sciences 1999, 54:M546-M553.

44. Gubitz G, Phillips S, Aguilar E: Discharge disposition of patients on an acute stroke unit. J Stroke Cerebrovasc Dis 1999, 8:330-335.

45. Hermans E, Diederiks JP, Philipsen H: Home care-a realistic alternative for bed-blocking stroke victims in acute hospital wards? The conceptions of caregivers in six disciplines concerned. Scand J Caring Sci 1996, 10:81-87.

46. Carter ND, Wade DT: Delayed discharges from Oxford city hospitals: who and why? Clin Rehabil 2002, 16:315-320.

47. Koffman J, Fulop NJ, Pashley D, Coleman K: No way out: the delayed discharge of elderly mentally ill acute and assessment patients in north and south Thames regions. Age Ageing 1996, 25:268-272.

48. McClaran J, Berglas RT, Franco ED: Long hospital stays and need for alternate level of care at discharge. Does family make a difference for elderly patients? Canadian Family Physician 1996, 42:449.

49. Falcone D, Bolda E, Leak SC: Waiting for placement: an exploratory analysis of determinants of delayed discharges of elderly hospital patients. Health Serv Res 1991, 26:339-374.

50. Jasinarachchi KH, Ibrahim IR, Keegan BC, Mathialagan R, McGourty JC, Phillips JR, Myint PK: Delayed transfer of care from NHS secondary care to primary care in England: its determinants, effect on hospital bed days, prevalence of acute medical conditions and deaths during delay, in older adults aged 65 years and over. BMC Geriatr 2009, 9:4.

51. Gruneir A, Bell CM, Bronskill SE, Schull M, Anderson GM, Rochon PA: Frequency and pattern of emergency department visits by long-term care residents-a population-based study. J Am Geriatr Soc 2010, 58:510-517.

52. Statistics Canada. A Portrait of Seniors in Canada. Ottawa:; 2006. http://www statcan.gc.ca/ads-annonces/89-519-x/index-eng.htm.

53. Travers CM, McDonnell GD, Broe GA, Anderson P, Karmel R, Duckett SJ, Gray LC: The acute-aged care interface: exploring the dynamics of 'bed blocking'. Australas J Ageing 2008, 27:116-120.

54. Sutherland JM, Crump RT: Exploring alternate level of care (ALC) and the role of funding policies: An evolving evidence base for Canada. In CHSRF series of reports on cost drivers and health system efficiency: paper 8. Ottawa:; 2011.

55. Lakhan $\mathrm{P}$, Jones M, Wilson A, Courtney M, Hirdes J, Gray LC: A prospective cohort study of geriatric syndromes among older medical patients admitted to acute care hospitals. J Am Geriatr Soc 2011, 59:2001-2008.

56. Ostry AS, Tomlin KM, Cvitkovich Y, Ratner PA, Park IH, Tate RB, Yassi A: Choosing a model of care for patients in alternate level care: caregiver perspectives with respect to staff injury. Can J Nurs Res 2004, 36:142-157.

57. Ostry AS, Yassi A, Ratner PA, Park I, Tate R, Kidd C: Work organization and patient care staff injuries: the impact of different care models for "alternate level of care" patients. Am J Ind Med 2003, 44:392-399.

58. Glasby J, Littlechild R, Pryce K: All dressed up but nowhere to go? Delayed hospital discharges and older people. J Health Serv Res Policy 2006, 11:52-58.

59. Somme D, Lazarovici C, Dramé M, Blanc $P$, Lang PO, Gauvain JB, Voisin T, Gonthier R, De Wazières B, Jeandel C, Couturier P, Blanchard F, Saint-Jean O: The geriatric patient: use of acute geriatrics units in the emergency care of elderly patients in France. Arch Gerontol Geriatr 2011, 52:40-45.

\section{doi:10.1186/1472-6963-12-172}

Cite this article as: Costa et al: Acute care inpatients with long-term delayed-discharge: evidence from a Canadian health region. BMC Health Services Research 2012 12:172.

\section{Submit your next manuscript to BioMed Central and take full advantage of:}

- Convenient online submission

- Thorough peer review

- No space constraints or color figure charges

- Immediate publication on acceptance

- Inclusion in PubMed, CAS, Scopus and Google Scholar

- Research which is freely available for redistribution

Submit your manuscript at www.biomedcentral.com/submit
C Biomed Central 